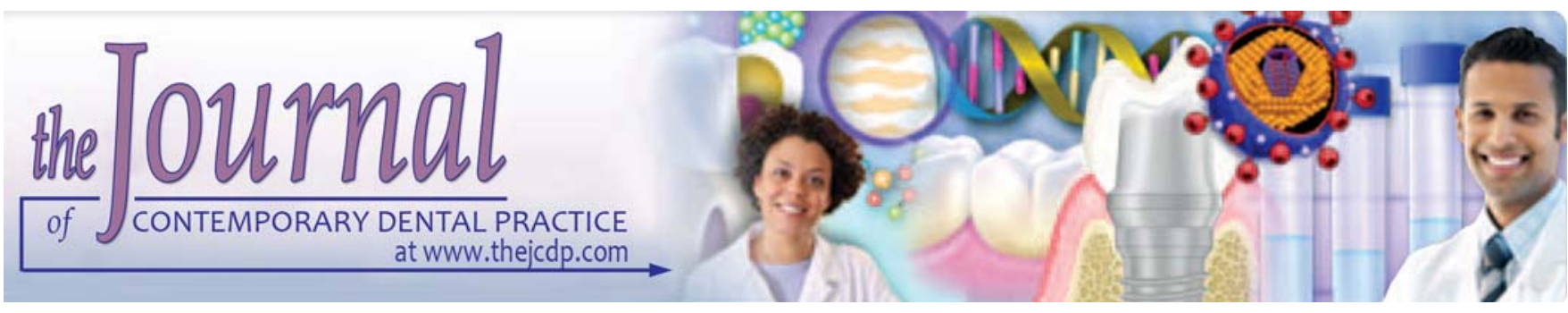

\title{
Epidemiological Survey on Edentulousness
}

\author{
N Simhachalam Reddy, Nallala Amarendra Reddy, R Narendra, Sashi Deepth Reddy
}

\section{ABSTRACT}

India has a large geriatric population of 77 millions, comprising $7.7 \%$ of its total population. One of the major handicaps in the elderly is loss of teeth, affecting their mastication, dietary intake and nutritional status.

Aims and objectives: The presentstudy was planned to assess the level of edentulousness, cause of edentulousness, denture wearing and denture needs of the middle and elderly in the society and study was correlated between habits and socioeconomic variables, diet and body mass index (BMI).

Materials and methods: A total of 500 subjects (random sampling) from dental outpatient were studied. A prepared questionnaire was developed, explained, interviewed and questions were filled personally.

Results: The level of edentulousness was found to be high in the subjects with low socioeconomic status and in advancing age with no significant difference between male and females. Another finding was very low level of denture wearing of $62 \%$ needing complete denture and partial denture only $10.4 \%$ of subjects wearing dentures.

Mixed diet population had higher level of edentulousness compared with vegetarians. The BMI was correlated with level of edentulousness.

Conclusion: The study clearly showed that there is lack of dental awareness, so dental education and motivation in very important. The study concludes that the need for prosthodontics care will increase due to the increase in life span.

This study is clinically significant with regard to knowing the root cause of edentulism, either partial or complete. O ut of $62 \%$ tooth loss, dental caries (37.4\%) topped the cause for tooth loss followed by combination of dental caries and periodontal disease $(12.2 \%)$.

Keywords: Edentulousness, Epidemiology, Body mass index, Denture wearing and diet.

How to cite this article: Reddy NS, Reddy NA, Narendra R, Reddy SD. Epidemiological Survey on Edentulousness. J Contemp Dent Pract 2012;13(4):562-570.

Source of support: Nil

Conflict of interest: None declared.

\section{INTRODUCTION}

Epidemiology is concerned with the course and outcome of diseases in individuals and groups in human population. The survey can be performed at small town level population or large national level population.

Last (1988) defined epidemiology as 'the study of the distribution and determinants of health-related status or events in specified populations and the application of the study to control health problems'.

Although a lot of epidemiological surveys have been conducted in dental caries and periodontal problems and data have been obtained, prosthetic sector has not gained any interest in epidemiology. O ne of the major handicaps in the elderly is loss of teeth, affecting their mastication, dietary intake and nutritional status. ${ }^{19}$

India has a large geriatric population of 77 million, comprising $7.7 \%$ of its total population. ${ }^{19}$ of the many issues concerning the welfare of an adult, 'Health' is one of the major concerns.

W eintraub and Buet (1985) used the term edentulism to describe the complete absence of natural teeth, regardless of whether they had been replaced or not. ${ }^{18}$

There are a number of factors known to be associated with oral health of the adult population, such as socioeconomic status, literacy level, smoking or chewing tobacco and al cohol consumption. 0 ther factors such as oral hygiene practices, social and cultural beliefs and attitudes, perceptions regarding oral health, function and philosophy of the dentists, can all influences oral health in the adult population. ${ }^{19}$

Epidemiological data on health and its related issues are very important in order to plan for future care. ${ }^{19}$ Nevertheless, the prosthetic sector has not gained the same epidemiological interest as caries and periodontitis and the data obtained, are often difficult to interpret. ${ }^{18}$ 
Prosthetic dentistry has a very dominant role in restorative dentistry. The prime objective of dental care is maintaining a natural functional dentition for life.

The percentage of edentulous people is expected to decrease in the coming decades as a result of improved oral health, where as the number of edentulous people will increase as a result of the strong increase in the aging population. ${ }^{13}$

Therefore, this study was planned to evaluate the level of edentulousness, denture wear habits and denture needs of adult population. It was planned to study the differences according to age and sex. As socioeconomic variables can influence the level of edentulousness, denture wearing and denture needs, these variables were also involved in the study.

\section{MATERIALS AND METHODS}

Selection of samples: The outpatient (OP) department in Sri Ramachandra Dental College, Porur, Chennai, was selected for the study. The cluster of villages close to this hospital made it logistically ideal to study the edentulous state of the population.

Target of the study population were 500 subjects (random sampling) from the dental OP.

The personel details and address of the subject were recorded. Educational status was listed as illiterate, school or college.

Socioeconomic status was graded as low, middle or high based on the income of the subject.

Socioeconomic status was recorded based on the guidelines set by Income Tax Department (U nion of India). Dietary preferences (veg or mixed diet) are recorded to assess its relation to level of edentulousness and denture wearing habits.

The correlation of systemic diseases like diabetes, hypertension, etc. with edentulism was analyzed.

Height and weight of each subject was recorded to calculate body mass index (BMI) as an indicator of nutritional status.

$$
\mathrm{BMI}=\frac{\text { Weight in kilogram }}{\text { Height in }\left(\mathrm{m}^{2}\right)}
$$

The level, cause and duration of edentulousness were recorded.

The effect of loss of tooth on esthetics, mastication and phonetics as felt by the subject were evaluated. The subject past experience with prosthodontic treatment modality was analyzed. A prepared questionnaire which contains 19 questions was developed and for all the subjects the study purpose was explained, interviewed and questions were filled personally.
The examination was conducted using basic diagnostic tools. (M outh mirror, straight probe, explorer No 21).

The operator examined the subjects by wearing mouth mask and disposable gloves.

Statistical software SPSS for windows (Version 11.5) was used for data analysis, Chi-square tests were performed and $p$-values were calculated for each parameter and the results were tabulated.

\section{RESULTS}

In order to plan for future health care provisions, for the society, collecting epidemiological data on health and its related issues are very important. Data on oral health that to particularly relate to prosthodontics is scant. Therefore, this study was planned.

\section{DISCUSSION}

The preservation of dentition can be justified on the following grounds that, 'teeth' are useful for maintenance of arch length, esthetics, maintenance of healthy oral environment, mastication, phonetics, etc.

Tooth loss is the dental equivalent of mortality. It is the end product of oral disease and it also reflects the attitudes of patients, availability and accessibility of dental care and socioeconomic status.

One of the major handicaps in the elderly of our population is loss of teeth, affecting their mastication, dietary intake and nutritional status.

The importance of this study is to establish base line data on the prevalence of edentulism in adult population, seeking Care.

A cluster of villages close to Sri Ramachandra Dental College and $\mathrm{H}$ ospital, made it logistically ideal for this study.

Previous studies ${ }^{20}$ have divided the subjects into 18 to 40 years (young adults), 41 to 60 years (middle adults) and $>61$ years (old adults), for the sake of convenience in classification. This present study also made use of this classification to segregate the sample size of 500 subjects (Fig. 1 and Table 1).

In this study, the number of male subjects were $232(46.4 \%)$ and the number of female subjects were $268(53.6 \%)$ (Fig. 2 and Table 2).

The younger age group (18-40 years) consisted of 315 subjects (63.0\%), middle age group (41-60 years) consisted of 146 subjects (29.2\%), old age group ( $>61$ years) consisted of 39 subjects $(7.8 \%)$.

A mong these samples, 141 (28.2\%) were illiterate, 276 $(55.2 \%)$ were educated up to or below secondary school level and 83 samples (16.6\%) were educated up to graduation (Fig. 3 and Table 3). 
In this survey 257 subjects $(51.4 \%)$ were of lowincome group, 228 subjects $(45.6 \%)$ were of middleincome group and there were mere 15 subjects (3.0\%) who belonged to high-income group (Fig. 4 and Table 4).

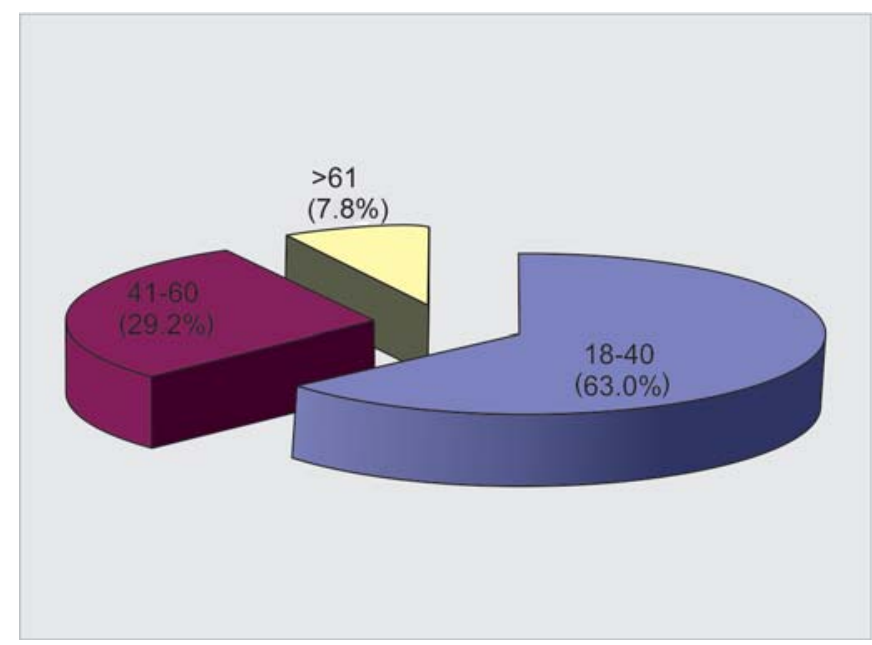

Fig. 1: Age in years

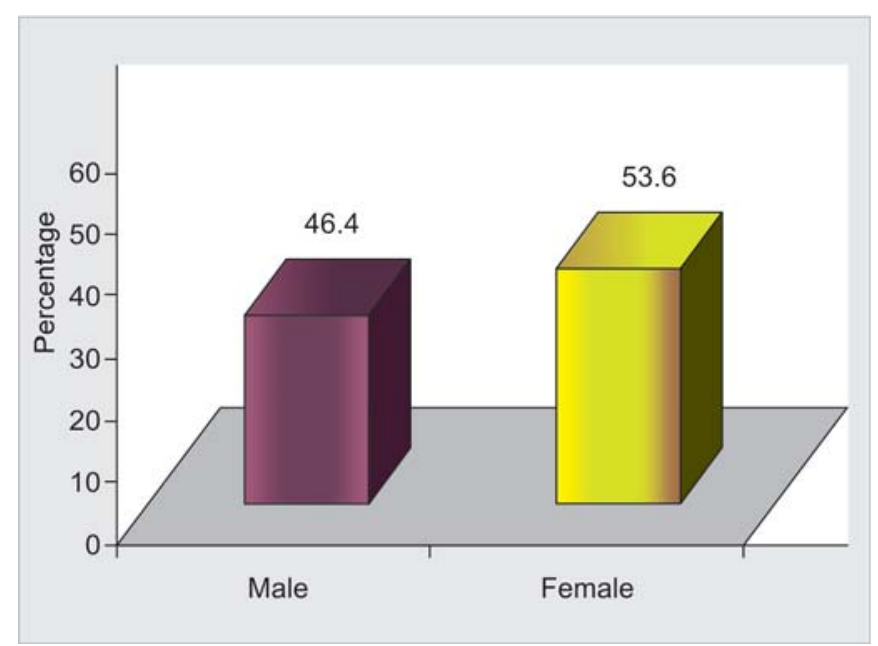

Fig. 2: Sex

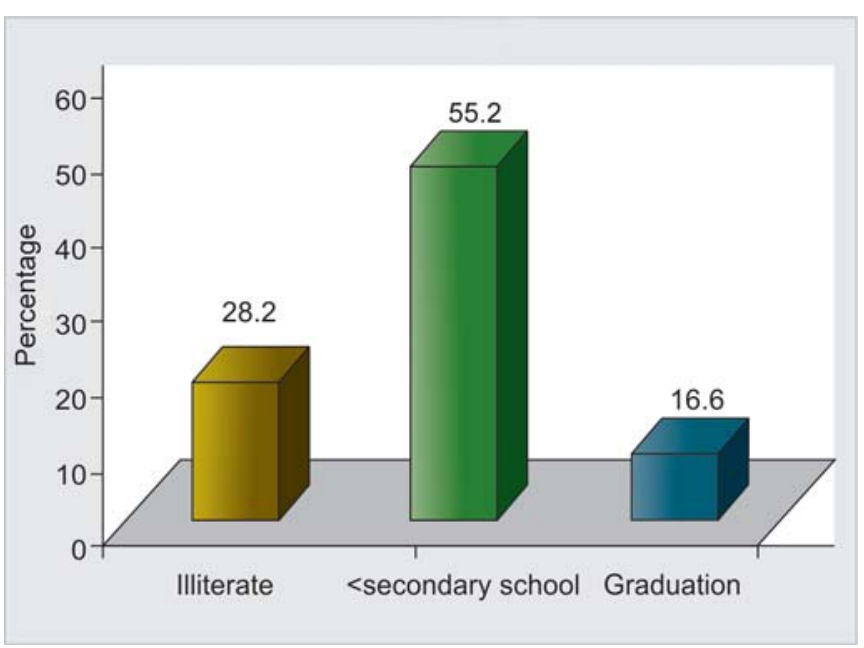

Fig. 3: Educational status of the subjects
A total of $70.6 \%$ of the total study population had desirable BMI. A total of $24.2 \%$ were under weight and $5.2 \%$ were found to be overweight (Fig. 5 and Table 5).

Studies by Georgia K J ohnson, ${ }^{8}$ Jerome Hlaber et al ${ }^{11}$ and $\mathrm{H}$ anioka $\mathrm{T}$ et al, ${ }^{9} \mathrm{clearly}$ mentioned the role of tobacco. Smoking is a risk factor for periodontitis. In this study, out of 500 subjects, 70 (14\%) were smokers, 23 of them (4.6\%) were tobacco chewers, 11 (2.2\%) were pan chewers, 19 of them $(3.8 \%)$ were both smokers and tobacco chewers and 377 samples $(75.4 \%)$ did not have any habits. Statistical analysis, 'Chi-square' test showed significant $p$-values $(p<0.05)$ when the edentulousness and habits were compared. Smokers always had more cases in level of edentulousness than other habits (Fig. 6 and Table 6).

A nother important finding seen in this study was that among the maxillary and mandibular arches, the edentulous state was more prevalent in mandibular arch $(19.2 \%)$ as against the maxillary arch (12.2\%). This was explained through previous studies. Cahen PM et al ${ }^{4}$ stated that the permanent mandibular first molar that erupted first into the

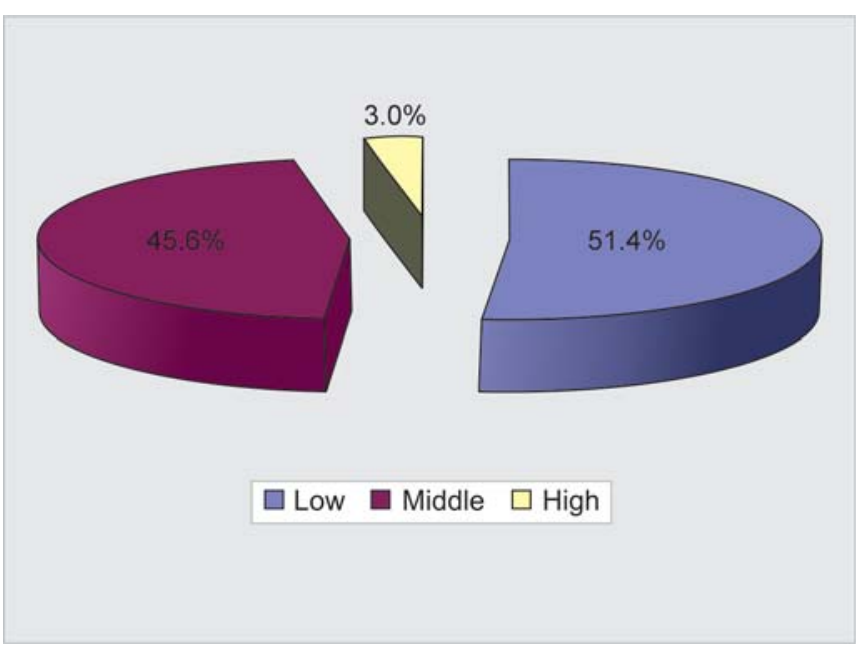

Fig. 4: Socioeconomic status

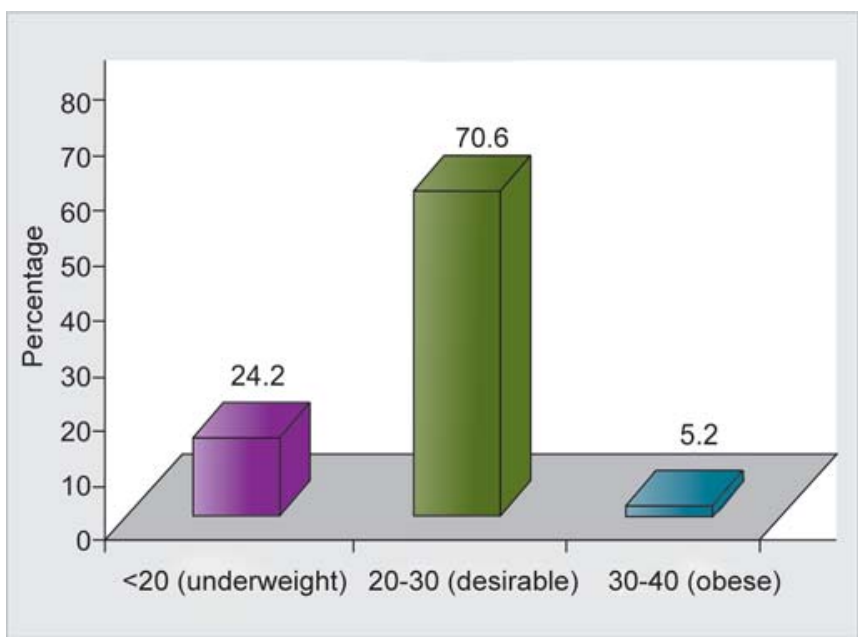

Fig. 5: Built (BMI) 
oral cavity was more prone to caries and food lodgement due to deep pits and fissures (Fig. 7 and Table 7).

The survey showed that $40.2 \%$ of subjects had problems due to loss of teeth. Out of them, majority of the subjects had problems in mastication (26\%), followed by esthetics and mastication (5.8\%) which showed similar findings as by A nnette Thomas-W eintraub, ${ }^{1}$ who stated that masticatory difficulty was the most frequently voiced complaint (Fig. 8 and Table 8).

A nother important finding was that out of $62 \%$ tooth loss, dental caries (37.4\%) topped the cause for tooth loss, followed by combination of dental caries and periodontal disease $(12.2 \%)$ which was in concurrence to the previous studies. ${ }^{4}$ Studies by $M$ adlena $M$ et al ${ }^{14}$ showed that decayed teeth were highest in age group of 45 to 64 years (Fig. 9 and Table 9).

Out of $62 \%$ of previous denture wearer, i.e. partially or totally edentulous, only $10.4 \%$ of the subjects were previous denture wearers, which indicate a high level of unawareness among the edentulous subjects of prosthodontic therapy. A

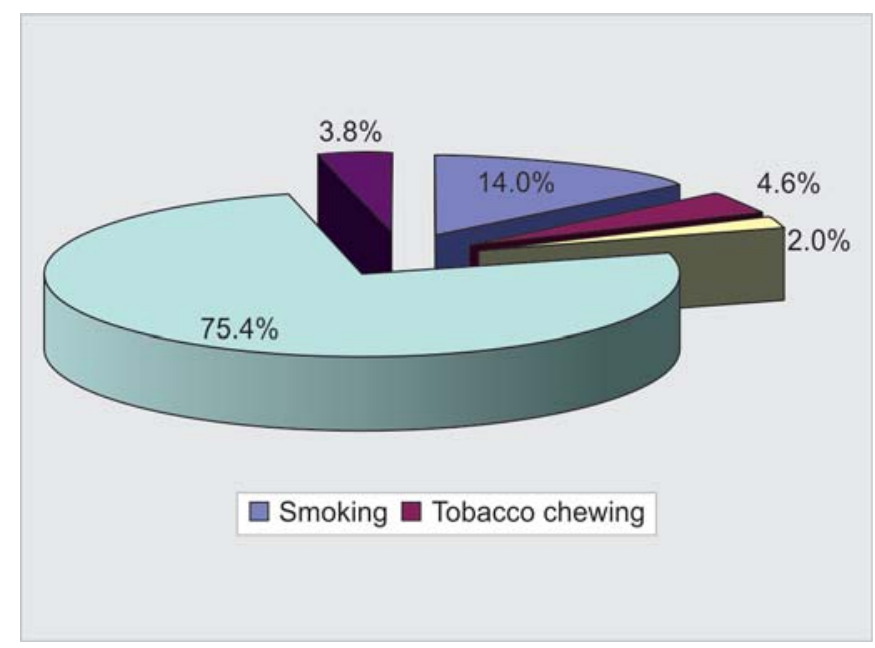

Fig. 6: Types of habits

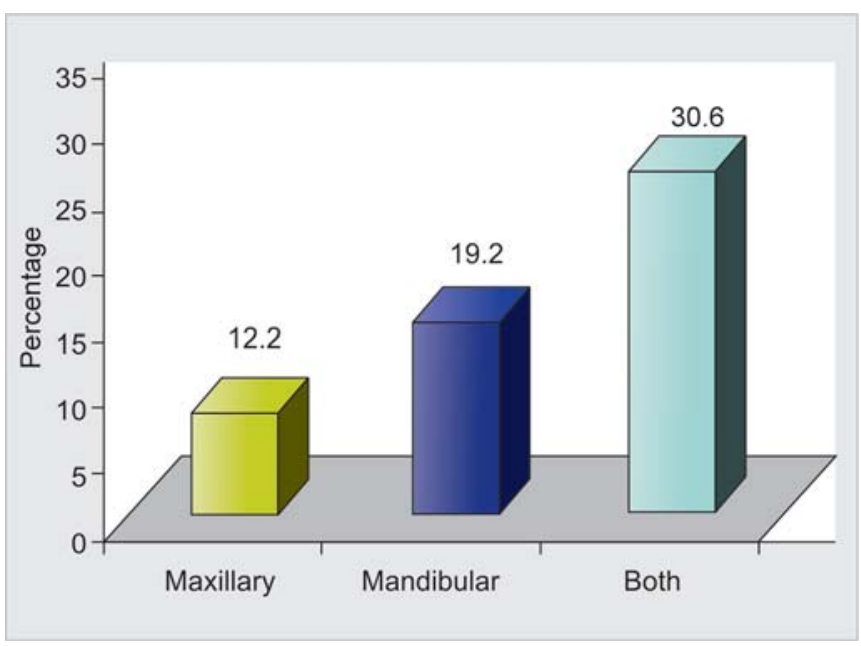

Fig. 7: Arch total of $51.6 \%$ of edentulous subjects were not wearing any previous dentures (Fig. 10 and Table 10).

A mong the nondenture wearers, $49.4 \%$ were willing to accept prosthodontic treatment and $12.6 \%$ of the subjects who were not using dentures were still not interested in prosthodontic treatment. This shows that majority of the subjects were willing to accept prosthodontic treatment, if they are motivated which according to previous study by Henry A Collett ${ }^{10}$ said that motivation is an important factor in denture treatment (Fig. 11 and Table 11).

The reasons cited by the subjects for not wearing dentures was mainly due to lack of awareness (26.6\%), cost factor by $7 \%$. This showed that 'lack of dental awareness' as by Shah $^{17}$ was primary cause of the edentulous state,

\begin{tabular}{lcc}
\multicolumn{3}{c}{ Table 1: Distribution of age } \\
\hline Age (years) & No. of subjects & Percentage \\
\hline $18-40$ & 315 & 63.0 \\
$41-60$ & 146 & 29.2 \\
$>61$ & 39 & 7.8 \\
\hline Total & 500 & 100.0 \\
\hline
\end{tabular}

\begin{tabular}{lcc}
\multicolumn{3}{c}{ Table 2: Sex distribution } \\
\hline Sex & No. of subjects & Percentage \\
\hline Male & 232 & 46.4 \\
Female & 268 & 53.6 \\
\hline Total & 500 & 100.0 \\
\hline
\end{tabular}

\begin{tabular}{|c|c|c|}
\hline \multicolumn{3}{|c|}{$\begin{array}{l}\text { Table 3: Educational status of subjects participated } \\
\text { in the study }\end{array}$} \\
\hline Educational status & No. of subjects & Percentage \\
\hline Illiterate & 141 & 28.2 \\
\hline$\langle$ Secondary school & 276 & 55.2 \\
\hline Graduation & 83 & 16.6 \\
\hline Total & 500 & 100.0 \\
\hline
\end{tabular}

\begin{tabular}{ccc}
\multicolumn{4}{c}{ Table 4: Socioeconomic status of the subjects } \\
\hline Socioeconomic status & No. of subjects & Percentage \\
\hline Low & 257 & 51.4 \\
Middle & 228 & 45.6 \\
High & 15 & 3.0 \\
\hline Total & 500 & 100.0 \\
\hline
\end{tabular}

\begin{tabular}{lcc}
\multicolumn{3}{c}{ Table 5: Built (BMI) } \\
\hline Built (BMI) & No. of subjects & Percentage \\
\hline$<20$ (under weight) & 121 & 24.2 \\
$20-30$ (desirable) & 353 & 70.6 \\
$30-40$ (obese) & 26 & 5.2 \\
\hline Total & 500 & 100.0 \\
\hline
\end{tabular}




\begin{tabular}{lcc}
\multicolumn{3}{c}{ Table 6: The types of habits } \\
\hline Habits & No. of subjects & Percentage \\
\hline S moking & 70 & 14.0 \\
Tobacco chewing & 23 & 4.6 \\
Pan chewing & 11 & 2.2 \\
None & 377 & 75.4 \\
S moking and tobacco & 19 & 3.8 \\
Chewing & & \\
\hline Total & 500 & 100.0 \\
\hline
\end{tabular}

either partial or completely edentulous state (Fig. 12 and Table 12).

Shah $\mathrm{N}$ et al ${ }^{19}$ showed that tooth loss increased with advancing age and was higher among the elderly subjects.

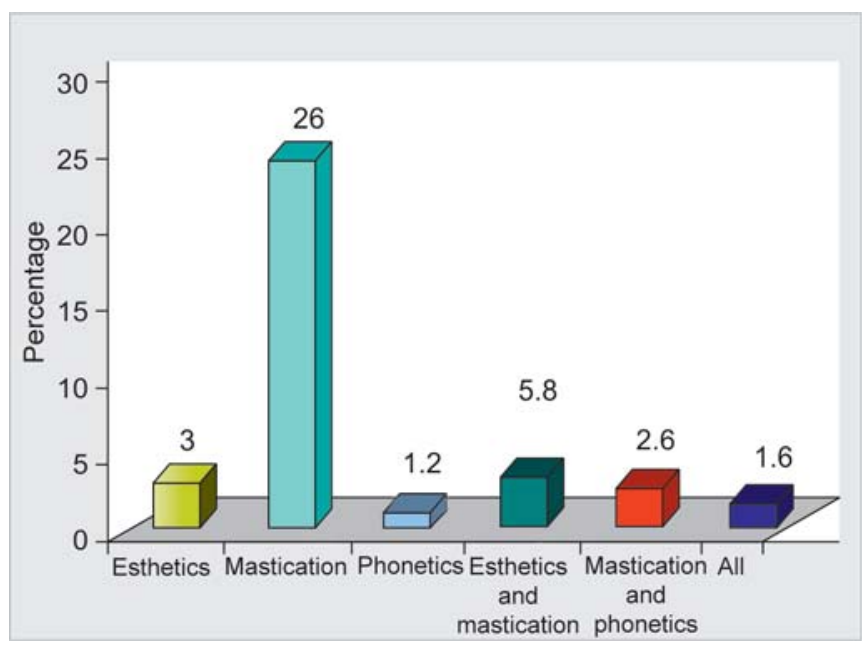

Fig. 8: Loss of tooth-type of problem

\begin{tabular}{lcc}
\hline Type of problem & No. of subjects & Percentage \\
\hline Esthetics & 15 & 3.0 \\
Mastication & 130 & 26.0 \\
Phonetics & 6 & 1.2 \\
Esthetics and mastication & 29 & 5.8 \\
Mastication and phonetics & 13 & 2.6 \\
All & 8 & 1.6 \\
\hline Total & 201 & 40.2 \\
\hline
\end{tabular}

Table 9: The cause of edentulousness

\begin{tabular}{lcc}
\multicolumn{3}{c}{ Table 9: The cause of edentulousness } \\
\hline Cause of & No. of subjects & Percentage \\
edentulousness & & \\
\hline Dental caries & 187 & 37.4 \\
Periodontal disease & 47 & 9.4 \\
Trauma & 14 & 2.8 \\
Dental caries and & 61 & 12.2 \\
Periodontal disease & & 0.2 \\
Dental caries and trauma & 1 & 62.0 \\
\hline Total & 310 & \\
\hline
\end{tabular}

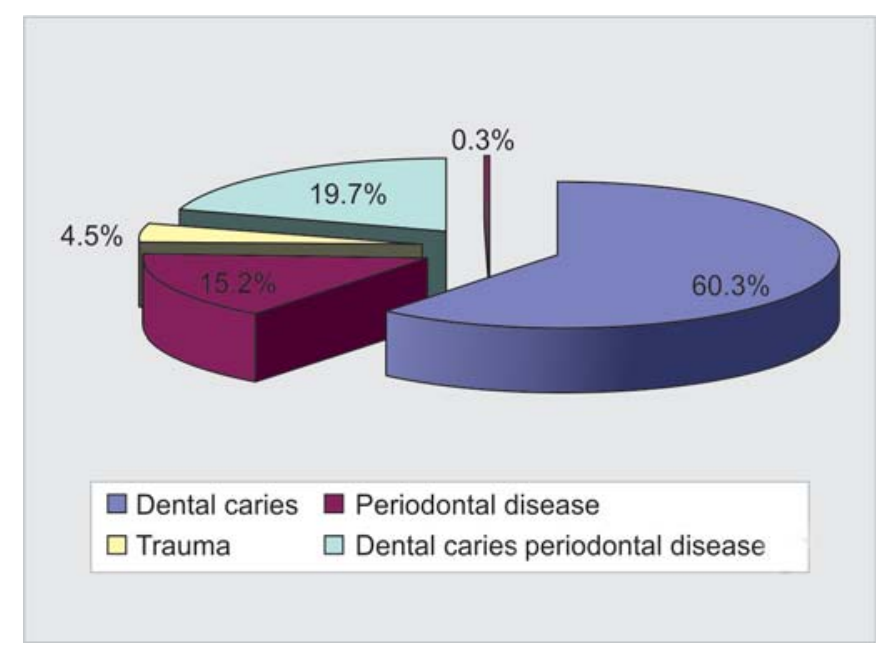

Fig. 9: Cause of edentulousness

Table 10: About previous denture wearer

\begin{tabular}{lcc}
\multicolumn{3}{c}{ Table 10: About previous denture wearer } \\
\hline $\begin{array}{l}\text { Are you a previous } \\
\text { denture wearer }\end{array}$ & No. of subjects & Percentage \\
\hline Yes & 52 & 10.4 \\
No & 258 & 51.6 \\
\hline Total & 310 & 62.0 \\
\hline
\end{tabular}

\begin{tabular}{lcc}
\multicolumn{3}{c}{ Table 11: Willing for prosthodontic treatment } \\
\hline $\begin{array}{l}\text { Prosthodontic } \\
\text { treatment }\end{array}$ & No. of subjects & Percentage \\
\hline Yes & 247 & 49.4 \\
No & 63 & 12.6 \\
\hline Total & 310 & 62.0 \\
\hline
\end{tabular}

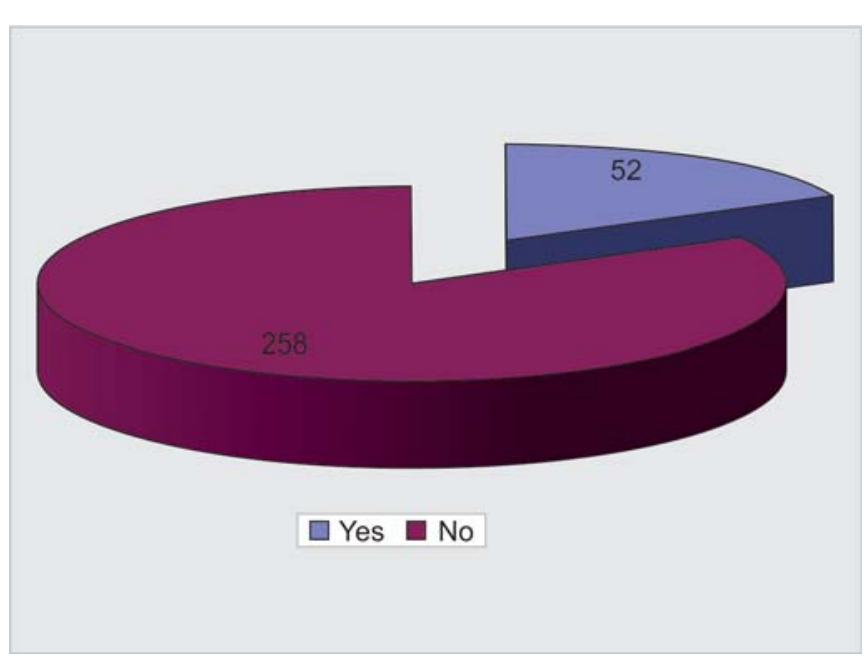

Fig. 10: Previous denture wearer 
When the level of edentulousness and the sex of subject were compared, out of the $46.4 \%$ male subjects, $21.8 \%$ were fully dentate and $24.6 \%$ subjects were partially or completely edentulous. In female subjects, out of 53.6, $16.2 \%$ were fully dentate whereas $37.4 \%$ were either partially or completely edentulous. So, in this study female subjects were more prone to edentulousness, showing statistical significant $p$-value. M any studies ${ }^{2,12}$ have showed that a higher prevalence of edentulism existed among women than man (Fig. 13 and Table 13).

When the level of edentulousness and socioeconomic status were compared, the majority of the subjects were from low-income group (51.4\%). Out of them, apart from $16.4 \%$ dentate subjects, the rest of the $35 \%$ were partially or totally edentulous. Out of $45.6 \%$ middle-income group, $24.6 \%$ were partially or completely edentulous. And of the $3 \%$ high income group, $2.4 \%$ of the subjects had missing teeth and $0.6 \%$ had no missing teeth. This showed that the level of edentulousness was seen more in low-income group and p-value was statistically significant and al so studies by A I$D$ wairi $Z^{3}$ suggest a significant relationship between sociodemographic variables and edentulism, with age, educational level and socioeconomic status playing vital roles in edentulism and denture demand (Fig. 14 and Table 14).

A nja A inamo ${ }^{2}$ stated that socioeconomic level was one of the reason associated with dental health. Workers and farmers were reported more often edentulous, than, senior sal aried employees. Even studies by D olan TA et al, ${ }^{5} \mathrm{G}$ ordan W Thompson et al ${ }^{7}$ stated that subjects with least education and lowest income are most likely to be edentulous. And also Evren BA et al ${ }^{6}$ through his study of 269 subjects found that, $51 \%$ of the subjects had low income and majority of $66.6 \%$ were edentulous.

The level of edentulousness and built of the patient (BM I) were compared and it was found that there was no role to be played by body mass index in leading to edentulous state. Studies by M ack F et al ${ }^{15}$ showed that the most significant risk factor for subjects with high B M I were hypertension and diabetes. Dental factors were not influenced by B M I but influenced by socioeconomic factor. In this study, $70.6 \%$ had desirable B M I. B ut out of the $70.6 \%$ subjects, $44.2 \%$ subjects still had missing teeth. This shows that apart from the BMI, more serious factors such as smoking, lack of awareness led to edentulousness. This was in concurrence with the previous studies by Shah $\mathrm{N}$ et al ${ }^{19}$ which shows that BMI does not correlate to level of edentulousness (Fig. 15 and Table 15).

When cause of edentulousness w ere examined and then compared with habits, smoking was the major cause
(16.1\%), followed by tobacco chewing $(5.2 \%)$ and pan chewing (3.2\%). Hanioka T et al ${ }^{9}$ in his study stated that tooth loss in adults was very similar in both males and females. However, the smoking habits associated with males was responsible for the tooth loss. Even in this study

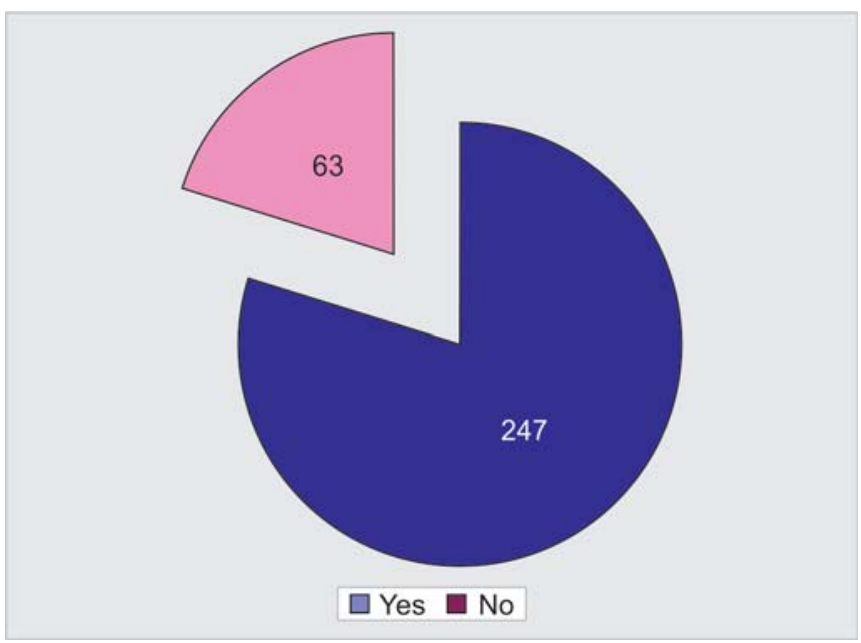

Fig. 11: Prosthodontic treatment

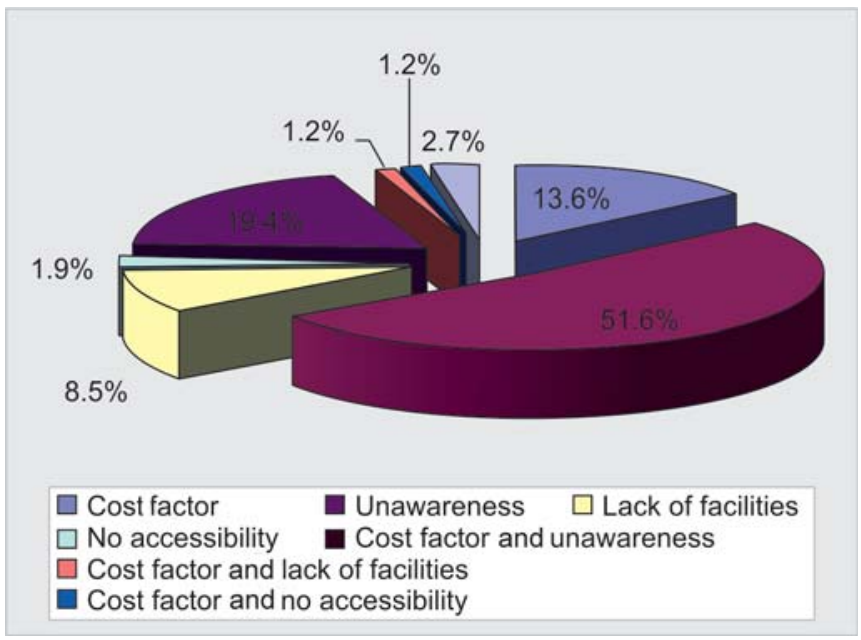

Fig. 12: Factors for not replacing the missing tooth

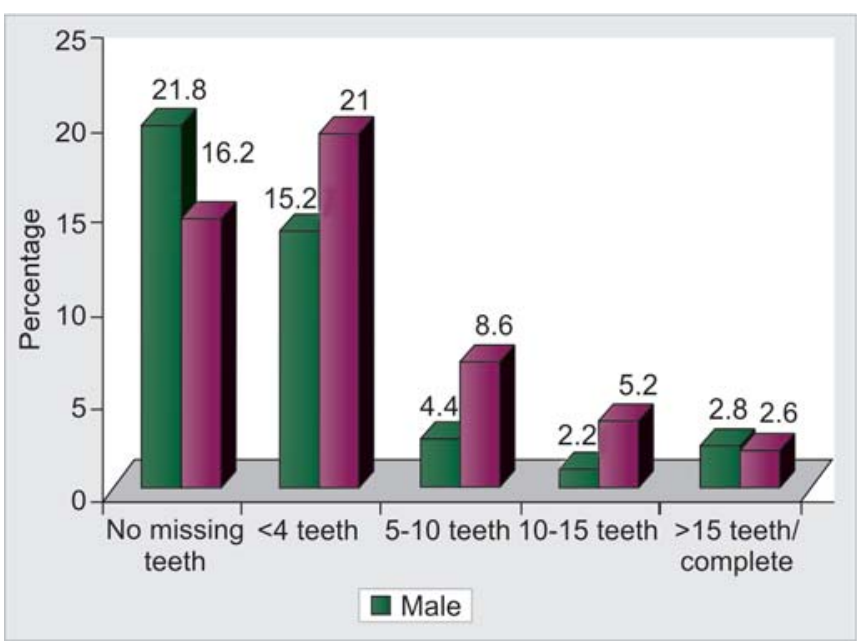

Fig. 13: Comparison of level of edentulousness and sex 
smoking was the major causing edentulousness (Fig. 16 and Table 16).

The dental profession recognizes difficulties peculiar to prosthetic patients as well as the attention required by seemingly limitless details of treatment. Though the

Table 12: Not replacing the missing teeth

S. no. Why did not replace No. of subjects Percentage your missing tooth

\begin{tabular}{llcr}
\hline 1 & Cost factor & 35 & 7.0 \\
2 & Unawareness & 133 & 26.6 \\
3 & Lack of facilities & 22 & 4.4 \\
4 & No accessibility & 5 & 1.0 \\
5 & $\begin{array}{l}\text { Cost factor } \\
\text { and unawareness }\end{array}$ & 50 & 10.0 \\
6 & $\begin{array}{l}\text { Cost factor } \\
\text { and lack of facilities }\end{array}$ & 3 & 0.6 \\
7 & $\begin{array}{l}\text { Unawareness and lack of } \\
\text { facilities, no accessibility }\end{array}$ & 7 & 1.4 \\
8 & $\begin{array}{l}\text { Lack of facilities and } \\
\text { no accessibility }\end{array}$ & 1 & 0.2 \\
9 & $\begin{array}{l}\text { Cost factor, unawareness } \\
\text { and lack of facilities } \\
10\end{array}$ & 1 & 0.2 \\
& $\begin{array}{l}\text { Cost factor, lack of } \\
\text { facilities and no accessibility }\end{array}$ & 1 & 0.2 \\
\hline & Total & 258 & 51.6 \\
\hline
\end{tabular}

\begin{tabular}{|c|c|c|c|}
\hline \multirow[t]{2}{*}{ Level of edentulousness } & \multicolumn{2}{|c|}{ Sex } & \multirow[t]{2}{*}{ Total } \\
\hline & Male & Female & \\
\hline No. missing teeth & $\begin{array}{c}109 \\
21.8 \%\end{array}$ & $\begin{array}{c}81 \\
16.2 \%\end{array}$ & $\begin{array}{c}190 \\
38.0 \%\end{array}$ \\
\hline$<4$ teeth & $\begin{array}{c}76 \\
15.2 \%\end{array}$ & $\begin{array}{c}105 \\
21.0 \%\end{array}$ & $\begin{array}{c}181 \\
36.2 \%\end{array}$ \\
\hline $5-10$ teeth & $\begin{array}{c}22 \\
4.4 \%\end{array}$ & $\begin{array}{c}43 \\
8.6 \%\end{array}$ & $\begin{array}{c}65 \\
13.0 \%\end{array}$ \\
\hline 10-15 teeth & $\begin{array}{c}44 \\
2.2 \%\end{array}$ & $\begin{array}{c}26 \\
5.2 \%\end{array}$ & $\begin{array}{c}37 \\
7.4 \%\end{array}$ \\
\hline $\begin{array}{l}>15 \text { teeth/ } \\
\text { complete }\end{array}$ & $\begin{array}{c}14 \\
2.8 \%\end{array}$ & $\begin{array}{c}13 \\
2.6 \%\end{array}$ & $\begin{array}{c}27 \\
5.4 \%\end{array}$ \\
\hline Total & $\begin{array}{c}232 \\
46.4 \%\end{array}$ & $\begin{array}{c}268 \\
53.6 \%\end{array}$ & $\begin{array}{c}500 \\
100.0 \%\end{array}$ \\
\hline
\end{tabular}

\begin{tabular}{lcccc}
\multicolumn{5}{c}{ Table 14: Compares level of edentulousness and } \\
socioeconomic status \\
Level of & \multicolumn{3}{c}{ Socioeconomic status } & Total \\
\cline { 2 - 4 } edentulousness & Low & Middle & High & \\
\hline No. missing & 82 & 105 & 3 & 190 \\
teeth & $16.4 \%$ & $21.0 \%$ & $0.6 \%$ & $38.0 \%$ \\
< 4 teeth & 94 & 78 & 9 & 181 \\
& $18.8 \%$ & $15.6 \%$ & $1.8 \%$ & $36.2 \%$ \\
5-10 teeth & 37 & 27 & 1 & 65 \\
& $7.4 \%$ & $5.4 \%$ & $0.2 \%$ & $13.0 \%$ \\
$10-15$ teeth & 28 & 9 & - & 37 \\
& $5.6 \%$ & $1.8 \%$ & - & $7.4 \%$ \\
$>15$ teeth/ & 16 & 9 & 2 & 27 \\
complete & $3.2 \%$ & $1.8 \%$ & $0.4 \%$ & $5.4 \%$ \\
\hline Total & 257 & 228 & 15 & 500 \\
& $51.4 \%$ & $45.6 \%$ & $3.0 \%$ & $100.0 \%$ \\
\hline
\end{tabular}

prosthodontists honor the standards of treatment, general public are not interested in them. The public is interested in getting the necessary minimal treatment at the lowest possible cost. These are the demands that the general population is placing on the services which, the dental professionals must provide and that prosthodontists in particular must try to meet.

Preventive dental care is al most nonexistent to the rural masses and vary in urban areas. There is no orientation of dental graduates toward the special needs to the older population. Therefore recommendation include, the establishment of continuing dental education programs on geriatric oral care; inclusion of a geriatric component in undergraduate and postgraduate curriculum; initiation of a diploma, certificate and degree courses in geriatric dentistry. Research on various aspects of ageing and age-related oral health problems; provision of preventive and curative treatment for various oral diseases to the elderly, etc. Studies by M usacchio $E$ et $\mathrm{al}^{16}$ also suggested that the high prevalence of edentulous subjects without prostheses

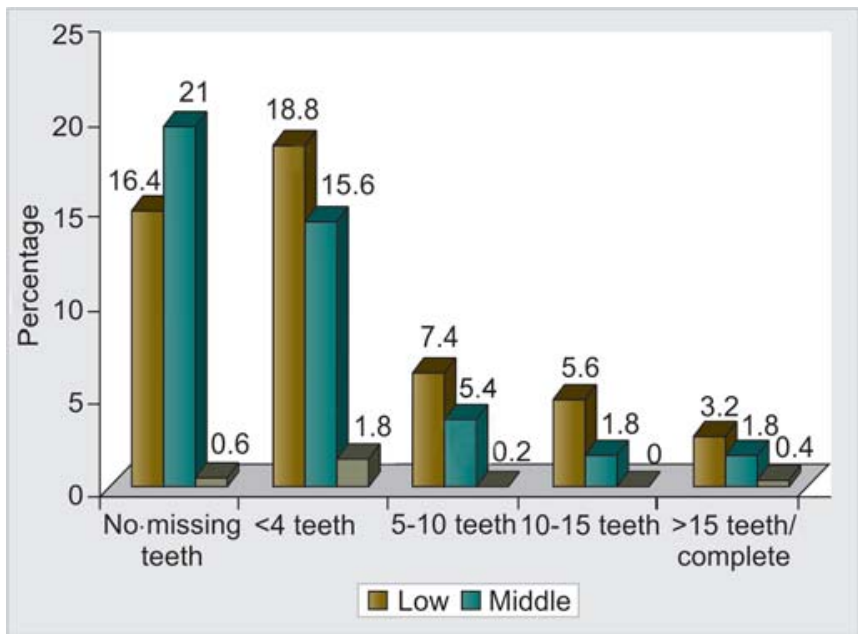

Fig. 14: Comparison of level of edentulousness and socioeconomic status

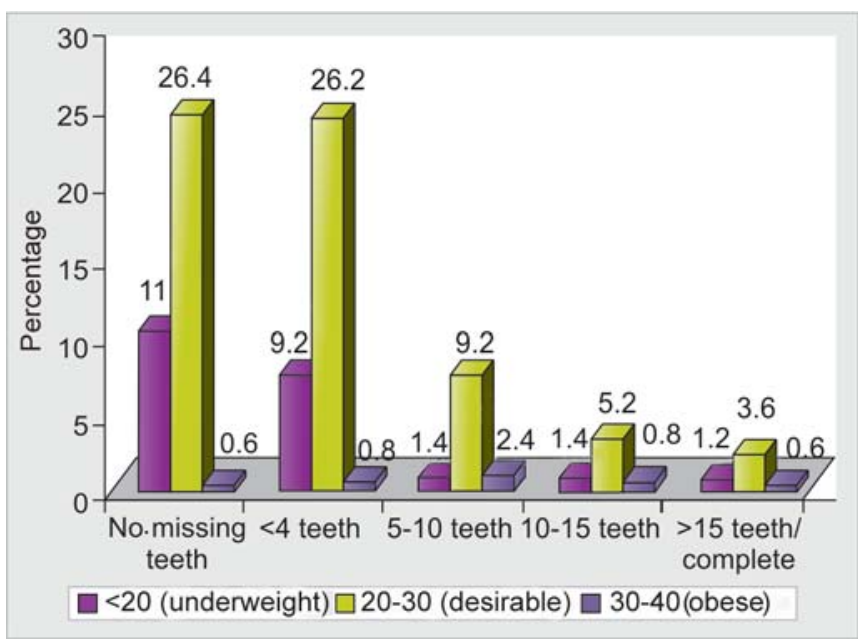

Fig. 15: Comparison of level of edentulousness and built (BMI) 
suggests a need for educational and social measures to improve patients attitudes to dental care and to encourage the use of prostheses among the elderly.

Oral health awareness and education programs should be conducted at the community level for every individual.

\begin{tabular}{lcccc}
\multicolumn{4}{c}{ Table 15: Comparison of level of edentulousness and } \\
Built (BMI) \\
\cline { 1 - 4 } $\begin{array}{c}\text { Level of } \\
\text { edentulousness }\end{array}$ & \multicolumn{3}{c}{ Built (BMI) } & Total \\
\cline { 2 - 4 } & $\begin{array}{c}<20 \\
\text { (under wt) }\end{array}$ & $\begin{array}{c}20-30 \\
\text { (desirable) }\end{array}$ & $\begin{array}{c}30-40 \\
\text { (obese) }\end{array}$ \\
\hline No. missing & 55 & 132 & 3 & 190 \\
teeth & $11.0 \%$ & $26.4 \%$ & $0.6 \%$ & $38.0 \%$ \\
<4 teeth & 46 & 131 & 4 & 181 \\
& $9.2 \%$ & $26.2 \%$ & $0.8 \%$ & $36.2 \%$ \\
5-10 teeth & 7 & 46 & 12 & 65 \\
& $1.4 \%$ & $9.2 \%$ & $2.4 \%$ & $13.0 \%$ \\
10-15 teeth & 7 & 26 & 4 & 37 \\
& $1.4 \%$ & $5.2 \%$ & $0.8 \%$ & $7.4 \%$ \\
$>15$ teeth/ & 6 & 18 & 3 & 27 \\
complete & $1.2 \%$ & $3.6 \%$ & $0.6 \%$ & $5.4 \%$ \\
\hline Total & 121 & 353 & 26 & 500 \\
& $24.2 \%$ & $70.6 \%$ & $5.2 \%$ & $100.0 \%$ \\
\hline
\end{tabular}

The role and proper method of oral hygiene practice, the negative efforts of various oral habits, especially tobacco habits, the need to replace missing teeth, care of artificial dentures and self examination of the oral cavity for early detection of oral precancers and cancers should be explained.

The future of prosthodontics, require some revamping of the concepts of delivery of prosthodontic services taking place. Present and future demands will not be met by dentists taught by dental faculties as they function today.

So, prosthodontists with extensive training and advanced clinical experience can meet the challenges of partial or complete edentulous state of the patients.

Periodical surveys in different parts of the country should be consistently undertaken, to evaluate the status of edentulism and the progress in attempts to curb it.

\section{SUMMARY AND CONCLUSION}

This study presents the results of an epidemiological survey. The data of the systemic disease, habits, problems due to edentulousness, prosthodontic treatment needs of the

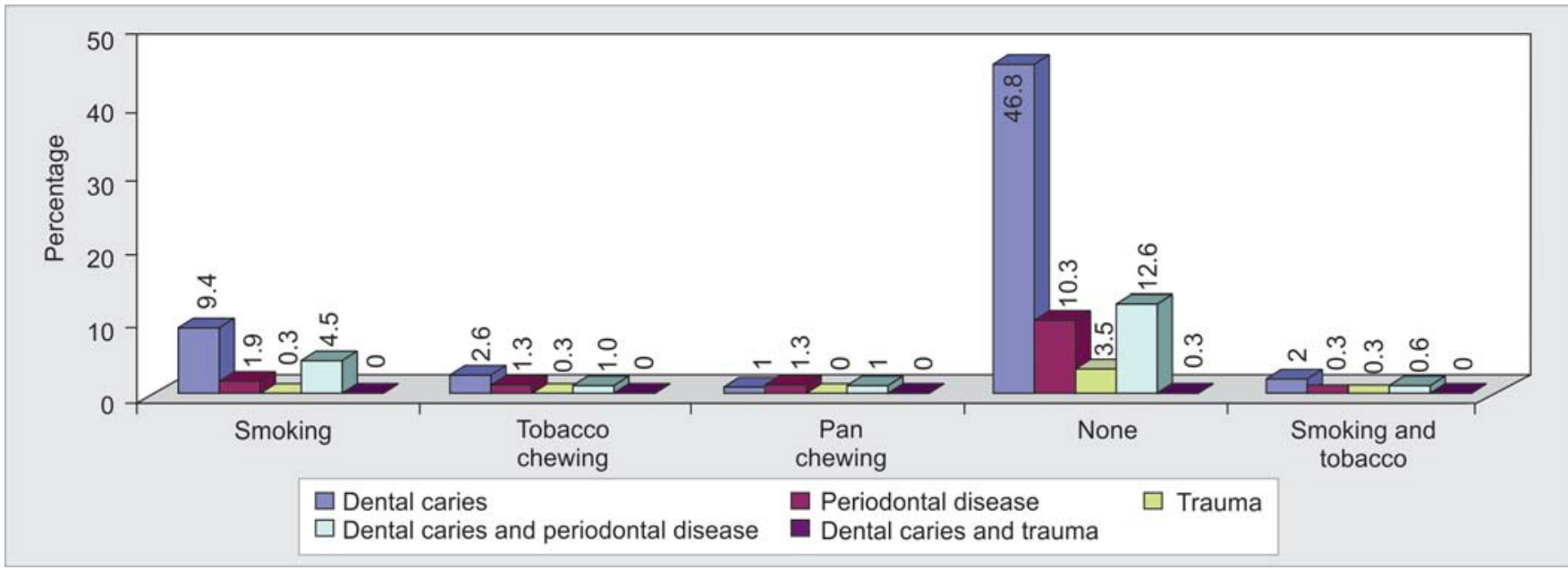

Fig. 16: Comparison of cause of edentulousness and habits

\begin{tabular}{|c|c|c|c|c|c|c|}
\hline \multirow[t]{2}{*}{ Cause of edentulousness } & \multicolumn{5}{|c|}{ Habits } & \multirow[t]{2}{*}{ Total } \\
\hline & Smoking & $\begin{array}{l}\text { Tobacco } \\
\text { chewing }\end{array}$ & $\begin{array}{c}\text { Pan } \\
\text { chewing }\end{array}$ & None & $\begin{array}{l}\text { Smoking and } \\
\text { to bacco chewing }\end{array}$ & \\
\hline \multirow[t]{2}{*}{ Dental caries } & 29 & 8 & 3 & 145 & 2 & 187 \\
\hline & $9.4 \%$ & $2.6 \%$ & $1.0 \%$ & $46.8 \%$ & $0.6 \%$ & $60.3 \%$ \\
\hline \multirow[t]{2}{*}{ Periodontal disease } & 6 & 4 & 4 & 32 & 1 & 47 \\
\hline & $1.9 \%$ & $1.3 \%$ & $1.3 \%$ & $10.3 \%$ & $0.3 \%$ & $15.2 \%$ \\
\hline \multirow[t]{2}{*}{ Trauma } & 1 & $0.3 \%$ & & 11 & 1 & 14 \\
\hline & $0.3 \%$ & 1 & & $3.5 \%$ & $0.3 \%$ & $4.5 \%$ \\
\hline \multirow{3}{*}{$\begin{array}{l}\text { Dental caries and } \\
\text { periodontal disease } \\
\text { Dental caries and trauma }\end{array}$} & 14 & 3 & 3 & 39 & 2 & 61 \\
\hline & $4.5 \%$ & $1.0 \%$ & $1.0 \%$ & $12.6 \%$ & $0.6 \%$ & $19.7 \%$ \\
\hline & & & & $\begin{array}{l}1 \\
03 \%\end{array}$ & & $\begin{array}{l}1 \\
0\end{array}$ \\
\hline \multirow{2}{*}{ Total } & 50 & 16 & 10 & 228 & 6 & 310 \\
\hline & $16.1 \%$ & $5.2 \%$ & $3.2 \%$ & $73.5 \%$ & $1.9 \%$ & $100.0 \%$ \\
\hline
\end{tabular}


subjects, in this study have provided the basic information that may help to throw light on some of the problems facing practice of prosthodontics.

In this study, it was observed that the subjects who were illiterate or the most educated up to or below secondary school level exhibited more amount of tooth loss or edentulousness when compared with subjects who were educated up to graduation.

Through this study it was found that loss of teeth and level of edentulousness were more prevalent among lowincome group subjects, followed by middle-income group and high-income group.

The results of the survey clearly stated that there is lack of dental awareness among the people. So, 'dental education and motivation' is the most important aspect of prosthodontic treatment.

To conclude, it can be stated that the need for prosthodontic care will increase due to this increase in life span.

Conducting surveys, dental education and motivation are important tools in the rural elderly to enlighten the availability of prosthetic services and to thoroughly eradicate the misconception that 'Tooth loss' is an unavoidable and inevitable part of the ageing process.

\section{REFERENCES}

1. Thomas-W eintraub A. Dental needs and dental service use patterns of an elderly endentulous population. J Prosthet Dent 1985;54:526-32.

2. A inamo $A$, Osterberg $T$. C hanging demographic and oral disease patterns and treatment needs in the scandinavian populations of old people. Int Dent J 1992;42:311-22.

3. AI-Dwairi ZN. Complete edentulism and socioeconomic factors in a J ordanian population. Int J Prosthodont 2010;23: 541-43.

4. Cahen PM , Frank RM, Turlot JC. A survey of the reasons for dental extractions in France. J Dent Res 1985;64:1087-93.

5. Dolan TA, Gilbert GH, D uncan RP Foerster. Risk indicators of edentulism, partial both loss and prosthetic status among black and white middle-aged and older adults. Community Dent O ral Epidemiol 2001;29:329-40.

6. Evren BA, Uludamar A, Iseri U, Ozkan YK. The association between socioeconomic status, oral hygiene practice, denture stomatitis and oral status in elderly people living different residential homes. A rch Gerontol Geriatr 2011;53:252-57.

7. Gordon W Thompson, Phil SJ Kriesel. The impact of the demographics of aging and the edentulous condition on dental care services. J Prosthet Dent 1998;79:56-69.

8. Georgia K Johnson, Nancy A Slach. Impact of tobacco use of periodontal status. J Dent Edu 2001;65:313-18.

9. Hanioka T, Ojima M, Tanaka K, A oyama H. A ssociation of total tooth loss with smoking, drinking alcohol and nutrition in elderly J apanese: A nalysis of national database. Gerodontology 2007;24:87-92.
10. Henry A Collett. M otivation: A factor in denture treatment. J Prosthet Dent 1967;17:5-15.

11. Jerome Haber, Julianne W attles, M aureen Crowley, Robert $M$ andell, Kaumudi J oshipura, Ralph L K ent. Evidence for cigarette smoking as a major risk factor for periodontitis. J Periodontal 1993;64:16-23.

12. Jane A W eintraub, B rain A B urt. O ral health status in the $U$ nited States: Tooth loos and edentulism. J Dent Edu 1985;49:368-78.

13. Kalk W, Van Rossum GM JM, Van Waas, M A J. Edentulism and preventive goals in the treatment of mutilate dentition. Int Dent J 1990;40:267-74.

14. M adlena $M$, H ermann $P$, J ahn M , Fejerdy $P$. C aries prevalence and tooth loss in Hungarian adult population: Results of a national survey. BM C Public Health 2008;21:364.

15. $M$ ack $F, A$ beygunawardhana $N, M$ undt $T$, Schwahn $C$, Proff $P$, Spassov A , K ocher T, B iffar R. The factors associated with body mass index in adults from the study of health in pomerania (SHIP-0), Germany. J Physiol Pharmacol 2008;59:5-16.

16. Musacchio $E$, Perissinotto $E, B$ inotto $P$, Sartori $L$, SilvaNetto F, Zambon S, M anzato E, Corti MC, Baggio G, Crepaldi $G$. Tooth loss in the elderly and its association with nutritional status, socioeconomic and lifestyle factors. A cta Odontol Scand 2007;65:78-86.

17. Naseem Shah. Geriatric oral health issues in India. Int Dent J 2001;51:212-18.

18. O wall B, M almo, Sweden. Prosthetic epidemiology. Int Dent J 1986;36:230-34.

19. Shah N, Parkash H, Sunderman KR. Edentulousness, denture wear and denture needs of Indian elderly-a community-based study. J Oral Rehabil 2004;31:467-76.

20. Williams SR. Essentials of nutrition and diet therapy. M osby, St. Louis: Times M iror; (5th ed) 302-05.

\section{ABOUT THE AUTHORS}

\section{N Simhachalam Reddy}

A ssociate Professor, Department of Prosthodontics, Government Dental College, RIM S, Kadapa, A ndhra Pradesh, India

\section{Nallala Amarendra Reddy}

Professor, Department of Prosthodontics, Pulla Reddy Dental College, Kurnool, Andhra Pradesh, India

\section{R Narendra}

Professor, D epartment of Prosthodontics, Government Dental College RIM S, K adapa, A ndhra Pradesh, India

\section{Sashi Deepth Reddy}

Associate Professor, Department of Prosthodontics, Government Dental College, RIM S, Kadapa, Andhra Pradesh, India

\section{CORRESPONDING AUTHOR}

N Simhachalam Reddy, A ssociate Professor, Department of Prosthodontics, H.No 502, Fifth Floor, Classic Towers, Prakash Nagar, Kadapa, A ndhra Pradesh, India, Phone: 9866446588 e-mail: drchalam_77@yahoo.co.in 